\title{
Improved Evaluation Index Systems for Public Physical Education
}

\author{
https://doi.org/10.3991/ijet.v16i03.20473 \\ Lin Wang, Weifeng Deng $\left({ }^{\bowtie}\right)$, Haijin Pan, \\ Hainan Vocational University of Science and Technology, \\ Haikou, China \\ Xue Deng \\ Xingtai Polytechnic College, Xingtai, China \\ $189762574770163 . \mathrm{com}$
}

\begin{abstract}
In view of the defects of existing evaluation index systems (EIS) for the teaching quality of public PE such as it's difficult for them to process fuzzy and uncertain information, this paper analyzed factors that can affect the teaching of public PE and extracted the key evaluation indices; then, it proposed a set of improved EISs for the teaching quality of public PE and constructed an evaluation model based on fuzzy system theory. Moreover, this paper put forward a few countermeasures for the improvement of public PE teaching quality, in the hopes of providing a good support for the said matter.
\end{abstract}

Keywords-Teaching quality, public physical education (PE), evaluation system, evaluation model

\section{Introduction}

Public PE lessons are an important part of professional physical education, which plays an important role in improving students' comprehensive physical quality and cultivating high-level sports professionals [1-3]. As modern society is developing rapidly and its demand for high-quality sports professionals is becoming increasingly urgent, modern education is also heading towards the direction of quality-orientated education, and more attention has been paid to public PE lessons [4-5]. In this context, the teaching of modern public PE lessons has become a hotspot in the field of pedagogy, and research results concerning the teaching mode, teaching method, teaching tool and teaching content of public PE have been achieved [6-7]. For example: Liu [8] discussed the process assessment of public PE lessons in colleges and universities in the context of the Sun Sports Program in China, and gave corresponding suggestions. Jiang and Yang [9] took Dali University as the research object to analyze current public PE lesson performance evaluation systems and discussed the countermeasures. Zhu [10] conducted a research on the teaching quality evaluation system of public PE courses in higher vocational colleges, and discussed the construction of public PE teaching quality evaluation system. With some local institutions of 
higher-learning as subjects, Liu et al. [11] discussed the construction of PE teacher teaching ability evaluation system, which provided a good reference for the research on public PE.

However, considering the complexity of the teaching process of public PE and the diverse and fuzzy features of the influencing factors of the teaching quality, there're still rooms for the research on the effective evaluation of public PE. Due to the existence of uncertain fuzzy information, the evaluation of public PE is a complex and fuzzy decision-making process. Although the existing decision-making methods have already achieved some typical engineering applications [12-15], due to the different application conditions and ranges, these methods usually have certain limitations. For this reason, based on previous research results and theoretical analysis, this paper probes deep into the problem of public PE lesson teaching system combining AHP [16-17] and fuzzy system theory [18-19], and discussed a fuzzy evaluation model of public PE.

The research content of this paper consists of 6 parts. The first part is a summary of the teaching of public PE lessons and its evaluation; the second part analyzed existing problems with public PE and its evaluation; the third part discussed a new evaluation system for the teaching of public PE lessons and gives specific indices; the fourth part explores a public PE lesson teaching evaluation model based on fuzzy system theory and proposes the implementation details; the fifth part analyzes some countermeasures of the improvement of the teaching quality of public PE lessons, which provides a good support for the improvement of public PE lesson quality; and the sixth part is the conclusion.

\section{Problems in Public PE Teaching and Evaluation}

\subsection{Evaluation purpose and PE connotation mismatching}

The purpose public PE in schools is to enable students to better enjoy sports activities, build up physical fitness, and cultivate perseverance and optimism. Through public PE lessons, students could obtain not only the basic sports knowledge, but also a healthy body and mentality. However, due to the influence of the traditional examination-oriented education philosophy, current PE teachers often put more emphasis on the exam scores, while neglecting the physical qualities and skills of students. As a result, not only did the public PE fail to achieve its due effect, worse still, sometimes it increases physical and psychological burdens on students. Moreover, in some schools, the entrance examinations include the sports performance. If the exams are only based on the students' physical fitness, it'll be helpful for improving their body health; however, if the exams are based on scores, such exam-orientated education mode that doesn't consider students' congenital physical differences will overburden the students. Therefore, the ultimate purpose of public PE is let students develop good physical exercise habits, strengthen their body functions and physical literacy; it shouldn't become a mere test form that increases burdens on students, and deprive them of the fun of sports, and this is just opposite to the original purpose of public PE. 


\subsection{Deviations in PE teachers' PE cognition}

An important purpose of the evaluation of PE is to supervise and assess the teaching work of PE teachers, so that they can find out their shortcomings during the teaching process in a timely manner, and understand the teaching links and content that should be improved. This has pointed out a clear direction for the improvement of the teaching work of PE teachers, and it's conductive to the design of teaching goals and content. Another purpose of PE evaluation is to examine students' learning situations and physical fitness, and make them realize of their own issues and aspects to be improved. However, the current PE evaluation is mostly result-oriented, the evaluation results are usually taken as the performance goal of PE teaching, and the teaching content of public PE is prepared just for the teaching assessment. This utilitarian tendency can make public PE boring and tedious; it will take away the fun of sports from students, affecting their participation and enthusiasm, thus lowering the teaching quality of public PE.

\subsection{Imperfect evaluation form}

Current PE evaluation process often uses one-time final evaluation to determine students' learning performance and teachers' teaching effect, although this evaluation form is simple and easy-to-operate, it has a few limitations. One is that it cannot reflect the learning situation of students in a timely manner, especially some students do not have a serious attitude towards learning during the semester, they only make efforts at the last minute; although a few of them might still get good scores, their learning is not systematic and the effect won't last. The second limitation is that it cannot truly reflect the teaching effect of public PE. As we all know, public PE is a systematic teaching and learning process. The teaching effect is reflected in multiple aspects such as teaching content, plan, organization, form and tool, etc.; and in some aspects, the effect is hidden and invisible. Therefore, one single evaluation form cannot fully reflect the teaching effect of public PE, and reliable evaluation results can only be obtained through comprehensive, systematic, and logical analysis.

\subsection{Inflexible evaluation standards}

The traditional evaluation standards of public PE are inflexible. On the one hand, they overemphasize the teaching results and teaching forms, while neglecting the evaluation of the teaching process; with the constant development of modern education technology, the requirements for sports education are changing all the time, and modern PE is attaching more importance to the link of teaching implementation; from the specific implementation process of teaching activities, we can more easily and timely discover the weak links of PE teaching and the major influencing factors of students' learning and then take targeted measures, and this is of great significance for improving the teaching quality of PE, the teaching ability of PE teachers and the teaching system of public PE lessons. On the one hand, traditional evaluation standards of public PE only focus on the learning results, while neglecting the individual 
differences of students. When formulating the evaluation standards, quantitative assessment is valued more than quality assessment. As we all know, the students' learning result is an important manifestation of the teaching effect, considering the student's individual physical differences, although their exam scores are different, the improvement of their learning effect might be the same, and such improvement can reflect the teaching effect and teaching level of PE teachers. Therefore, when formulating the evaluation standards of public PE, it is necessary to take into account the dynamic development of public PE and the differences in the assessment objects, so that the evaluation standards of PE could have good adaptability.

\section{Construction of the Teaching Evaluation System of Public PE}

The teaching evaluation of public PE is a very complex system project, which involves not only many influencing factors, but also multiple evaluation perspectives, and this situation has resulted in that different education stages usually have different evaluation content and standards, and the components of the teaching evaluation system are dynamic and developing. In view of the different evaluation perspectives and standards, this paper holds that, a complete teaching evaluation system for public PE should have four parts, namely the teacher perspective, student perspective, administrator perspective, and society perspective; and the evaluation content should have three parts, namely the preparation, implementation, and effects.

\subsection{Public PE teaching evaluation system based on the perspective of teachers}

Table 1. Public PE teaching evaluation system based on the perspective of teachers

\begin{tabular}{|c|c|c|}
\hline Evaluation system & Evaluation aspects & Evaluation indices \\
\hline \multirow{18}{*}{$\begin{array}{l}\text { The public PE teaching } \\
\text { evaluation system based } \\
\text { on the perspective of } \\
\text { teachers S1 }\end{array}$} & \multirow{6}{*}{ Preparation } & Professional quality of PE teachers \\
\hline & & Teaching preparation before class \\
\hline & & Teaching planning \\
\hline & & Teaching goal formulation \\
\hline & & Syllabus and teaching scheme preparation \\
\hline & & $\begin{array}{l}\text { Cognition of teaching tasks and knowledge of student } \\
\text { situations }\end{array}$ \\
\hline & \multirow{5}{*}{ Implementation } & Imparting of teaching content \\
\hline & & Application of teaching methods \\
\hline & & Use of intelligent teaching tools \\
\hline & & Interactive teaching \\
\hline & & Teaching feedback \\
\hline & \multirow{7}{*}{ Effects } & Teaching task completion \\
\hline & & Excellent rate of students \\
\hline & & Pass rate of students \\
\hline & & Excellent textbooks \\
\hline & & Excellent courses \\
\hline & & Teaching environment/atmosphere \\
\hline & & Teaching reform \\
\hline
\end{tabular}


The public PE teaching evaluation system based on the perspective of teachers analyzes the teaching of public PE lessons from the perspective of PE teachers, its specific content is shown in Table 1.

\subsection{Public PE teaching evaluation system based on the perspective of students}

The public PE teaching evaluation system based on the perspective of students analyzes the teaching of public PE lessons from the perspective of PE students, its specific content is shown in Table 2.

Table 2. Public PE teaching evaluation system based on the perspective of students

\begin{tabular}{|c|c|c|}
\hline Evaluation system & Evaluation aspects & Evaluation indices \\
\hline \multirow{16}{*}{$\begin{array}{l}\text { The public PE teaching eval- } \\
\text { uation system based on the } \\
\text { perspective of students } S_{2}\end{array}$} & \multirow{3}{*}{ Preparation } & Teaching content is fully prepared \\
\hline & & Teaching plan is systematic \\
\hline & & Teaching direction is extensible \\
\hline & \multirow{5}{*}{ Implementation } & Teaching content reception \\
\hline & & Professional content expansion \\
\hline & & Good classroom atmosphere \\
\hline & & Increase in learning interest \\
\hline & & Timely problem solving \\
\hline & \multirow{8}{*}{ Effects } & Ability to master professional knowledge \\
\hline & & Sports skill level \\
\hline & & Ability to master technical movements \\
\hline & & Innovation ability \\
\hline & & Autonomous learning ability \\
\hline & & Knowledge absorption \\
\hline & & Coordination ability \\
\hline & & Learning rhythm control \\
\hline
\end{tabular}




\subsection{Public PE teaching evaluation system based on the perspective of} administrators

Table 3. Public PE teaching evaluation system based on the perspective of administrators

\begin{tabular}{|c|c|c|}
\hline Evaluation system & Evaluation aspects & Evaluation indices \\
\hline \multirow{19}{*}{$\begin{array}{l}\text { The public PE teaching } \\
\text { evaluation system based on } \\
\text { the perspective of adminis- } \\
\text { trators } S_{3}\end{array}$} & \multirow{4}{*}{ Preparation } & Ability to regulate syllabus \\
\hline & & Matching of teaching content and teaching goals \\
\hline & & Teaching knowledge reserve \\
\hline & & Teaching work preparation \\
\hline & \multirow{7}{*}{ Implementation } & Classroom environment and teaching effect \\
\hline & & Knowledge about students' learning situations \\
\hline & & Rich teaching content \\
\hline & & Scientific teaching methods \\
\hline & & Intelligent teaching tools \\
\hline & & Logical teaching tasks \\
\hline & & Correct teaching attitude \\
\hline & \multirow{8}{*}{ Effects } & High-level teaching reform programs undertaken \\
\hline & & High-level teaching awards received \\
\hline & & Employment rate of PE students \\
\hline & & Loss rate of PE students \\
\hline & & $\begin{array}{l}\text { Times of participation in high-level sports competi- } \\
\text { tions of students }\end{array}$ \\
\hline & & $\begin{array}{l}\text { Awards of high-level sports competitions received } \\
\text { by students }\end{array}$ \\
\hline & & Satisfaction of teaching supervisors \\
\hline & & Sports competitiveness and reputation \\
\hline
\end{tabular}

The public PE teaching evaluation system based on the perspective of students analyzes the teaching of public PE lessons from the perspective of PE administrators, its specific content is shown in Table 3.

\subsection{Public PE teaching evaluation system based on the perspective of society}

The public PE teaching evaluation system based on the perspective of society analyzes the teaching of public PE lessons from the perspective of the society, its specific content is shown in Table 4. 
Table 4. Public PE teaching evaluation system based on the perspective of the society

\begin{tabular}{|c|c|c|}
\hline Evaluation system & Evaluation aspects & Evaluation indices \\
\hline \multirow{13}{*}{$\begin{array}{l}\text { The public PE teaching } \\
\text { evaluation system based } \\
\text { on the perspective of the } \\
\text { society } S_{4}\end{array}$} & \multirow{3}{*}{ Preparation } & Advanced teaching idea \\
\hline & & The teaching goal has the features of the times \\
\hline & & Faculty construction \\
\hline & \multirow{5}{*}{ Implementation } & The teaching content has the features of the times \\
\hline & & Ability to combine theory with practice \\
\hline & & Ability to integrate teaching with research \\
\hline & & Ability to satisfy social requirements \\
\hline & & Competitiveness in the field of profession \\
\hline & \multirow{5}{*}{ Effects } & Social contribution of students \\
\hline & & $\begin{array}{l}\text { Students can match with the requirements of social } \\
\text { development }\end{array}$ \\
\hline & & Social satisfaction \\
\hline & & Conversion rate of teaching results \\
\hline & & $\begin{array}{l}\text { Ability to improve comprehensive quality of sports } \\
\text { talents }\end{array}$ \\
\hline
\end{tabular}

\section{Establishment of Teaching Evaluation Model for Public PE}

\subsection{Evaluation index set and scheme set for public PE}

To evaluate the teaching quality of public PE of multiple evaluation objects, reasonable evaluation standards and indices should be selected according to the objective situations of the teaching of public PE. Based above-mentioned guidance principles and the constructed evaluation index systems, here it's assumed that there are n evaluation indices of the teaching quality of public PE, the $\mathrm{j}$-th index is represented by uj, then the evaluation index set $\mathrm{U}$ of the teaching quality of public $\mathrm{PE}$ is:

$$
\mathbf{U}=\left\{u_{1}, \cdots, u_{j}, \cdots, u_{n}\right\}
$$

Assume there are a total of $\mathrm{m}$ objects participating in the evaluation of the teaching quality of public PE, then each evaluation object can be regarded as a decisionmaking plan about the evaluation index set, therefore, the scheme set $\mathrm{C}$ of the evaluation objects of public PE can be expressed as:

$$
\mathbf{C}\left\{C_{1}, \cdots, C_{i}, \cdots, C_{m}\right\}
$$

\subsection{Weights of evaluation indices}

In the evaluation index set $U$, each evaluation index has different effects on the evaluation result; in order to evaluation these different effects, it's necessary to assign different weight values to different evaluation indices of public PE. The AHP method has the characteristics of simple calculation, reliable results, and the calculation data are easy to obtain, therefore, this paper adopted AHP [20-22] to obtain the weight 
values of the evaluation indices of public PE. The specific implementation process is as follows.

First, using the expert scoring method, the degrees of the importance of any two evaluation indices were compared in pairs, and the importance of the $\mathrm{i}$-th evaluation index with respect to the $\mathrm{j}$-th evaluation index is marked as $a_{i j}$, then, a judgement matrix $\mathbf{A}$ of the evaluation indices of public PE can be obtained as:

$$
\mathbf{A}=\left[a_{i j}\right]_{n x n}=\left[\begin{array}{ccccc}
a_{11} & \cdots & a_{1 i} & \cdots & a_{1 n} \\
\vdots & \vdots & \vdots & \vdots & \vdots \\
a_{i 1} & \cdots & a_{i i} & \cdots & a_{i n} \\
\vdots & \vdots & \vdots & \vdots & \vdots \\
a_{n 1} & \cdots & a_{n i} & \cdots & a_{n n}
\end{array}\right]
$$

where, $n$ is the number of evaluation indices of public PE, it satisfies $1 \leq i, j \leq n$.

Under normal conditions, the value of aij is assigned using 1-9 scales, and it satisfies aij=1/aji, aii=1.

Second, the weight sequence $\mathrm{W}$ of the evaluation indices of public PE could be obtained as:

$$
\mathbf{W}=\left(w_{1}, \cdots, w_{i}, \cdots, w_{n}\right)^{T}
$$

where,

$$
w_{i}=\frac{\sum_{j=1}^{n}\left(a_{i j} / \sum_{i=1}^{n} a_{i j}\right)}{\sum_{i=1}^{n} \sum_{j=1}^{n}\left(a_{i j} / \sum_{i=1}^{n} a_{i j}\right)}
$$

Then, judgement matrix A is subject to consistency check, and the maximum eigenvalue $\lambda \max$ of judgement matrix A could be obtained as:

$$
\lambda_{\max }=\frac{1}{n} \sum_{i=1}^{n} \frac{(\mathbf{A} * \mathbf{W})_{i}}{w_{i}}
$$

If it satisfies:

$$
C R<0.1
$$

wherein,

$$
\begin{aligned}
& C I=\frac{\lambda_{\text {max }}-n}{n-1} \\
& C R=C I / R I
\end{aligned}
$$


The value of random consistency index RI can be selected from the corresponding table according to the value of $n$.

If it satisfies:

$$
C R \geq 0.1
$$

It indicates that the judgement matrix A does not meet the requirements of the consistency check, the obtained weight value of the evaluation index is invalid, the judgement analysis needs to be conducted again.

\subsection{Normalization of evaluation indices of public PE}

Because the values of the obtained evaluation indices are often fuzzy values, this paper adopted the triangular fuzzy numbers to express the fuzzy values. Assume Vij is the initial value of the evaluation index of the $i$-th evaluation object with respect to the $\mathrm{j}$-th evaluation index, it can be expressed as:

$$
V_{i j}=\left\langle v_{i j}^{L E}, v_{i j}^{M I}, v_{i j}^{R I}\right\rangle
$$

where, $v_{i j}^{M I}$ represents the most accurate value or the optimal value of the $\mathrm{i}$-th evaluation object with respect to the j-th evaluation index, $v_{i j}^{L E}$ is the left deviation of $v_{i j}^{M I}$, $v_{i j}^{\mathrm{RI}}$ is the right deviation of $v_{i j}^{M I}$.

The initial judgment data matrix can be obtained as:

$$
\mathbf{V}=\left[\begin{array}{ccccc}
\left\langle v_{11}^{L E}, v_{11}^{M I}, v_{11}^{R I}\right\rangle & \ldots & \left\langle v_{1 i}^{L E}, v_{1 j}^{M I}, v_{1 j}^{R I}\right\rangle & \ldots & \left\langle v_{1 n}^{L E}, v_{1 n}^{M I}, v_{1 n}^{R I}\right\rangle \\
\ldots & \vdots & \vdots & \vdots & \ldots \\
\left\langle v_{i 1}^{L E}, v_{i 1}^{M I}, v_{i 1}^{R I}\right\rangle & \ldots & \left\langle v_{i j}^{L E}, v_{i j}^{M I}, v_{i j}^{R I}\right\rangle & \ldots & \left\langle v_{i n}^{L E}, v_{i n}^{M I}, v_{i n}^{R I}\right\rangle \\
\ldots & \vdots & \vdots & \vdots & \ldots \\
\left\langle v_{m 1}^{L E}, v_{m 1}^{M I}, v_{m 1}^{R I}\right\rangle & \ldots & \left\langle v_{m j}^{L E}, v_{m j}^{M I}, v_{m j}^{R I}\right\rangle & \ldots & \left\langle v_{m n}^{L E}, v_{m n}^{M I}, v_{m n}^{R I}\right\rangle
\end{array}\right]
$$

If the $\mathrm{j}$-th public PE evaluation index is a benefit-type index, after it has been subject to the dimensionless processing, the normalized value Uij is obtained as:

$$
U_{i j}=\left\langle u_{i j}^{L E}, u_{i j}^{M I}, u_{i j}^{R I}\right\rangle=\left\langle\frac{u_{i j}^{L E}}{\max _{1 \leq i \leq m}\left(v_{i j}^{R I}\right)}, \frac{u_{i j}^{M I}}{\max _{1 \leq i \leq m}\left(v_{i j}^{R I}\right)}, \frac{u_{i j}^{R I}}{\max _{1 \leq i \leq m}\left(v_{i j}^{R I}\right)}\right\rangle
$$

If the $\mathrm{j}$-th public PE evaluation index is a cost-type index, after it has been subject to the dimensionless processing, the normalized value Uij is obtained as:

$$
U_{i j}=\left\langle u_{i j}^{L E}, u_{i j}^{M I}, u_{i j}^{R I}\right\rangle=\left\langle\frac{\min _{1 \leq i \leq m}\left(v_{i j}^{L E}\right)}{u_{i j}^{R I}}, \frac{\min \left(v_{i \leq m}^{L E}\right)}{u_{i j}^{M I}}, \frac{\min \left(v_{i \leq m}^{L E}\right)}{u_{i j}^{L E}}\right\rangle
$$


After normalization, the judgment matrix can be obtained as:

$$
\mathbf{U}=\left[\begin{array}{ccccc}
\left\langle u_{11}^{L E}, u_{11}^{M I}, u_{11}^{R I}\right\rangle & \ldots & \left\langle u_{1 i}^{L E}, u_{1 j}^{M I}, u_{1 j}^{R I}\right\rangle & \ldots & \left\langle u_{1 n}^{L E}, u_{1 n}^{M I}, u_{1 n}^{R I}\right\rangle \\
\ldots & \vdots & \vdots & \vdots & \ldots \\
\left\langle u_{i 1}^{L E}, u_{i 1}^{M I}, u_{i 1}^{R I}\right\rangle & \ldots & \left\langle u_{i j}^{L E}, u_{i j}^{M I}, u_{i j}^{R I}\right\rangle & \ldots & \left\langle u_{i n}^{L E}, u_{i n}^{M I}, u_{i n}^{R I}\right\rangle \\
\ldots & \vdots & \vdots & \vdots & \ldots \\
\left\langle u_{m 1}^{L E}, u_{m 1}^{M I}, u_{m 1}^{R I}\right\rangle & \ldots & \left\langle u_{m j}^{L E}, u_{m j}^{M I}, u_{m j}^{R I}\right\rangle & \ldots & \left\langle u_{m n}^{L E}, u_{m n}^{M I}, u_{m n}^{R I}\right\rangle
\end{array}\right]
$$

\subsection{Fuzzy evaluation process of public PE}

According to the fuzzy system theory, for the $j$-th public PE evaluation index, the corresponding fuzzy membership degree function $\delta(\mathrm{Uij})$ can be expressed as:

$$
\delta\left(U_{i j}\right)=\left\{\begin{array}{lc}
\frac{U_{i j}-u_{j}^{M I}(O)+u_{j}^{L E}(O)}{u_{j}^{L E}(O)} & u_{j}^{M I}(O)-u_{j}^{L E}(O) \leq U_{i j} \leq u_{j}^{M I}(O)+u_{j}^{R I}(O) \\
0 & U_{i j} \notin\left[u_{j}^{M I}(O)-u_{j}^{L E}(O), u_{j}^{M I}(O)\right] \\
1 & U_{i j}=u_{j}^{M I}(O) \\
\frac{u_{j}^{M I}(O)+u_{j}^{R I}(O)-U_{i j}}{u_{j}^{R I}(O)} & u_{j}^{M I}(O) \leq U_{i j} \leq u_{j}^{M I}(O)+u_{j}^{R I}(O)
\end{array}\right.
$$

where, $v_{j}^{M I}(O)$ represents the optimal value of the $\mathrm{j}$-th evaluation index, $v_{j}^{L E}(O)$ is the left deviation of $v_{j}^{M I}(O), v_{j}^{\mathrm{RI}}(O)$ is the right deviation of $v_{j}^{M I}(O)$.

Then for the $\mathrm{j}$-th evaluation index of public PE, the fuzzy distance Dij between the i-th evaluation object and the optimal triangular fuzzy number [23-26] is:

$$
D_{i j}=\sqrt{\frac{1}{3}\left(\left(d_{i j}^{L E}\right)^{2}+\left(d_{i j}^{M I}\right)^{2}+\left(d_{i j}^{R I}\right)^{2}\right)}
$$

where,

$$
\left\{\begin{array}{l}
d_{i j}^{L E}=\left(u_{i j}^{M I}(O)-u_{i j}^{L E}(O)\right)-\left(u_{j}^{M I}(O)-u_{j}^{L E}(O)\right) \\
d_{i j}^{M I}=u_{i j}^{M I}(O)-u_{j}^{M I}(O) \\
d_{i j}^{R I}=\left(u_{i j}^{M I}(O)+u_{i j}^{R I}(O)\right)-\left(u_{j}^{M I}(O)+u_{j}^{R I}(O)\right)
\end{array}\right.
$$

According to the physical meaning of fuzzy distance, greater Dij value indicates longer distance between the i-th evaluation object and the optimal triangular fuzzy number; and smaller Dij value indicates shorter distance between the i-th evaluation object and the optimal triangular fuzzy number. Based on this, the fuzzy nearness $\tau \mathrm{ij}$ between the i-th evaluation object and the optimal triangular fuzzy number could be obtained as: 


$$
\tau_{i j}=1-D_{i j}
$$

Then, the weighted fuzzy comprehensive correlation degree $\sigma \mathrm{i}$ of the i-th evaluation object of public PE can be expressed as:

$$
\sigma_{i}=\sum_{j=1}^{n}\left(w_{j} \times \tau_{i j}\right)=\sum_{j=1}^{n}\left(w_{j} \times\left(1-D_{i j}\right)\right)
$$

According to the establishment process of the model, the greater the value of $\sigma \mathrm{i}$, the better the public PE teaching quality of the i-th evaluation object, and vice versa. Therefore, according to the size of $\sigma \mathrm{i}$, the optimal evaluation object of public PE could be obtained.

\section{Measures to Improve the Teaching Quality of Public PE}

Using the above-established index systems and model, we can evaluate the public PE teaching quality of evaluation objects and obtain the corresponding analysis results. For those evaluation objects with inadequate public PE teaching quality, targeted strategic analysis and proper improvement measures are required to improve their teaching effects and level of public PE. This paper holds that, such improvement measures need to consider two aspects: the quality of theoretical teaching, and the quality of practical teaching. Public PE lessons generally involve the content of multiple subjects, including sports basics, sports techniques, and sport sociology, etc.; and the teaching content covers a wide range, such as basic sports knowledge, sport morphology, exercise physiology, sports biochemistry, sports biomechanics, sports medicine, sports psychology, sport pedagogy and philosophy, sport statistics, and sports history, etc. For this reason, to do a good job in the theoretical teaching of public PE, this paper proposes to take measures from the following aspects:

1. Increase knowledge reserves of sports students and enhance knowledge absorption:

For sports students, their test scores are generally composed of two parts: the physical test scores and cultural class scores. Besides cultural lessons, students have to spend a lot of time on sports training, especially for students with specialties in sports, the time they spent on this aspect is quite different from others, which has resulted in that their cultural knowledge reserve is relatively deficient, and thus affecting their learning of many professional courses; in particular, when they are learning theoretical knowledge in public PE lessons, they would have difficulty in learning specialized knowledge such as sports morphology knowledge, sports physiology knowledge, sports biochemistry knowledge, sports biomechanics knowledge, sports medicine knowledge, sports psychology knowledge, sport pedagogy and philosophy knowledge, sport statistics knowledge, and sports history knowledge, etc. By setting up preparatory courses before the PE course, the knowledge shortage problem can be solved using online teaching methods, students can use their vacation time, after school hours or spare times for learning; we can input the information of the students 
into intelligent online learning platforms such as chaoxing.com, MOOC, ke.qq.com, and Flipped Classroom, etc., and assign course learning tasks for them. Moreover, the online and offline teaching methods could be integrated to increase interaction between teachers and students and enhance knowledge absorption.

2. Consider the employment of students based on the teaching of sports knowledge:

Generally speaking, sports students do not have much career choices. Some of them do not have a clear development direction or proper employment orientation when they just enrolled, which has resulted in that some of them get lost in the learning process of public PE lessons and waste their learning time. Students usually have questions and doubts about the courses during the learning process of public PE lessons, therefore, it's suggested to give more detailed explanations when they choose their PE courses, it'll be better if examples of real cases could be provided, in such case, sports students could select their PE lessons more flexibly and independently according to their own development directions, not just blindly follow the choice of others or make choices out of inaccurate first impression of the course names. At the same time, when formulating sports student training plans, the schools should fully consider the students' employment directions, and formulate the teaching schemes based on their employment expectations; when arranging the lessons, they should consider both the students' characteristics and the social requirements. For instance, the sports major can refer to the student training plans of some engineering majors, arrange basic courses and professional basic courses in earlier stages, and subdivide the disciplines in later stages, one example is that the sports major can be subdivided into sports teachers, coaches, professional athletes, rehabilitation trainers, etc., and different training plans should be formulated for these different subdivisions.

3. Reasonably plan the public PE lessons and improve teaching methods:

The course content of public PE is relatively rich; therefore, its teaching plans have the special features of the sports profession, and it requires to combine more theoretical and practical knowledges. Since the knowledge teaching of PE should be systematic and logical, it needs a gradual process to lay a solid foundation for the cultivation of high-level sports professionals. Only by reasonably and scientifically planning the public PE lessons can they become a systematic and logical teaching system. In addition, proper teaching methods should be adopted from two aspects, on the one hand, from the PE teachers' perspective, they should think hard and figure out how to make the course more vivid and interesting, so as to trigger students' interest in learning and make them have a correct learning attitude; for example, teachers can use multiple teaching methods such as classroom discussion, homework assignment, social investigation, and multimedia teaching; and the assessment methods should not be limited to paper examinations; other examination forms such as oral examinations, open-book examinations and practical exercises are all assessment methods that are suitable for $\mathrm{PE}$, and they can truly stimulate the potential of students, and understand their learning status. On the other hand, PE teachers should reasonably arrange the course time, different from other disciplines, sports lessons are greatly affected by the environ- 
ment, therefore, it needs suitable seasons, venues, and equipment to form a good teaching environment; moreover, besides the learning of theoretical knowledge, sports students need to do professional exercises, and reasonably arranged class time allows them to keep a good learning state and concentrate on learning.

4. Do a good job in the practice link of public PE and improve the ability of system training:

Besides theoretical learning, the most important part of the practice teaching of PE is the professional training of the students, no doubt sports students have to pass a series of selections to be enrolled in sports major, before entering the learning of next stage, they generally have their respective specialties, and this has determined that before entering colleges, they have already had excellent physical and professional qualities. However, some sports students get slack in their training and fail to take the opportunity provided by colleges, they haven't continued the systematic training, which resulted in that their basic physical qualities and skills had not been effectively improved. For this reason, it is necessary to set sports training as a compulsory course for sports majors in every semester, so as to ensure that they could effectively improve their basic physical qualities and skills in the learning process of public PE; meanwhile, we can also consider to set a few selective professional training courses, as well as some curriculum activities such as fun games to encourage students to learn and train.

5. Increase resource input in public PE and improve the teaching quality:

An important measure to improve the teaching competitiveness of public PE is to increase the input of teaching resources, which is a basic guarantee for the teaching activities of public PE. This paper holds that, to increase resource input in public PE, we must do a good job in the following aspects: first, strengthen the faculty of public $\mathrm{PE}$, introduce or cultivate high-quality and competent professional teachers, and construct a teaching team of public PE with a good hierarchical structure; second, strengthen the construction of supporting facilities for public PE, thereby providing a good support for PE teaching and effectively improving the learning effect of PE lessons; third, increase material, financial and manpower input in the curriculum planning of public PE, so as to provide effective support for teaching activity implementation, teaching scheme planning, and teaching result transformation of public PE lessons, and thereby promoting the completion of teaching tasks and plans and improving the teaching quality of public PE. Moreover, besides these measures, we can also consider to improve the teaching concept, teaching management system, curriculum system construction and student management of public PE combining with the characteristics of the times. 


\section{Conclusion}

The works of this paper are mainly reflected in the following aspects: first, it analyzed factors that can affect the teaching quality of public PE and constructed a few improved evaluation index systems from multiple perspectives, which provided an important support for the perfection of the evaluation index system of public PE; second, based on the fuzzy system theory, it adopted AHP to propose a teaching quality evaluation model for public PE, which realized the processing of fuzzy information during the teaching evaluation process; third, it gave a few measures to improve the teaching quality of public PE, which has good guidance and reference significance.

\section{$7 \quad$ Acknowledgement}

2019 Hainan Provincial Higher Education Scientific Research Project (HnKy2019104).

This paper was supported by 2019 Hainan Provincial Higher Education Scientific Research Project (Grant No.: HnKy2019-104).

\section{$8 \quad$ References}

[1] Egan, C.A., Webster, C.A., Stewart, G.L., Weaver, R.G., Russ, L.B., Brian, A., Stodden, D.F. (2019). Case study of a health optimizing physical education-based comprehensive school physical activity program. Evaluation and Program Planning, 72: 106-117. https:// doi.org/10.1016/j.evalprogplan.2018.10.006

[2] Han, K. (2020). Evaluation of teaching quality of college physical education based on analytic hierarchy process, International Journal of Emerging Technologies in Learning, 15(10): 86-99.

[3] Yuan, X.W., Shao, H.L. (2019). Investigation and analysis of College Students' motivation in selecting public physical education courses-Taking China Three Gorges University as an example. Contemporary Sports Technology, 9(17): 76-80. https://doi.org/10.16655/j.cn $\underline{\text { ki.2095-2813.2019.17.076 }}$

[4] Gorozidis, G.S., Tzioumakis, Y.S., Krommidas, C., Papaioannou, A.G. (2020). Facebook group PETCoN (Physical Education Teacher Collaborative Network). An innovative approach to PE teacher in-service training: A self-determination theory perspective. Teaching and Teacher Education, 96: 1-16. https://doi.org/10.1016/j.tate.2020.103184

[5] Guo, H. (2020). Effect of curriculum planning for physical education in colleges on innovation ability, International Journal of Emerging Technologies in Learning, 15(12): 103-115.

[6] Dai, P., Ying, L. (2019). Investigations on the current situation of basketball teaching in public physical education in Huainan Normal University. Journal of Huainan Normal University, 21(2): 98-101.

[7] Dai, C. (2020). Bulletin of Sport Science \& Technology, 28(2): 44+88. https://doi.org/10.1 9379/j.cnki.issn.1005-0256.2020.02.021 
[8] Liu, G.Y. (2020). Research on the process assessment of Public Physical Education in Colleges and universities from the perspective of sunshine sports. Contemporary Sports Technology, 10(1): 64, 66. https://doi.org/ 10.16655/j.cnki.2095-2813.2020.01.064

[9] Jiang, F.Y., Yang, Y.L. (2020). Research on the current situation and Countermeasures of the evaluation system of Public Physical Education in Dali University. Contemporary Sports Technology, 10(7): 189-191. https://doi.org/10.16655/j.cnki.2095-2813.2020.07.1 89

[10] Zhu, Q.F. (2018). Study on Construction of Teaching Quality Evaluation System of Public Physical Education in Higher Vocational Colleges. Journal of Changzhou Vocational College of Information Technology, 17(5): 20-22. https://doi.org/10.3969/j.issn.16722434.2018.05.006

[11] Liu, J.F., Hou X.C., Ma, Z.J. Chen, X.H. (2019). Research on the Evaluation System of Public PE Teachers'Teaching Ability in Local Colleges and Universities in Heilongjiang Province. Journal of Mudanjing Teachers College (Natural Sciences Edition), 2019(3): 7780. https://doi.org/10.3969/j.issn.1003-6180.2019.03.018

[12] Yadav, V., Kalbar, P.P., Karmakar, S., Dikshit, A.K. (2020). A two-stage multi-attribute decision-making model for selecting appropriate locations of waste transfer stations in urban centers. Waste Management, 114: 80-88. https://doi.org/10.1016/j.wasman.2020.05. $\underline{024}$

[13] Shukla, S., Mohanty, B.K., Kumar, A. (2017). A Multi Attribute Value Theory approach to rank association rules for leveraging better business decision making. Procedia computer science, 122: 1031-1038. https://doi.org/10.1016/j.procs.2017.11.470

[14] Park, K., Kremer, G.E.O., Ma, J. (2018). A regional information-based multi-attribute and multi-objective decision-making approach for sustainable supplier selection and order allocation. Journal of Cleaner Production, 187: 590-604. https://doi.org/10.1016/j.jclepro. $\underline{2018.03 .035}$

[15] Baranitharan, P., Ramesh, K., Sakthivel, R. (2019). Multi-attribute decision-making approach for Aegle marmelos pyrolysis process using TOPSIS and Grey Relational Analysis: Assessment of engine emissions through novel Infrared thermography. Journal of Cleaner Production, 234: 315-328. https://doi.org/10.1016/j.jclepro.2019.06.188

[16] Wang, W.X. (2019). Site selection of fire stations in cities based on geographic information system (GIS) and fuzzy analytic hierarchy process (FAHP). Ingénierie des Systèmes d'Information, 24(6): 619-626. https://doi.org/10.18280/isi.240609

[17] Xie, Z.L., Yin, H.K. (2018). Selection of optimal cloud services based on quality of service ontology. Ingénierie des Systèmes d'Information, 23(6): 127-141. https://doi.org/10.3166/ ISI.23.6.127-141

[18] Calderaro, V., Lamberti, F., Galdi, V., Piccolo, A. (2018). Power flow problems with nested information: An approach based on fuzzy numbers and possibility theory. Electric Power Systems Research, 158: 275-283. https://doi.org/10.1016/j.epsr.2018.01.008.

[19] Li, Z.L., Zhou, Y., Bao, R. (2019). An image classification method based on optimized fuzzy bag-of-words model. Traitement du Signal, 36(3): 239-244. https://doi.org/10. 18280/ts.360306

[20] Yang, Z.H. (2020). Analysis of the impacts of open residential communities on road traffic based on AHP and fuzzy theory. Ingénierie des Systèmes d'Information, 25(2): 183-190. https://doi.org/10.18280/isi.250205

[21] Barić, D., Pižeta, F. (2018). An AHP model for level crossing design. International Journal of Safety and Security Engineering, 8(1): 65-76. https://doi.org/10.2495/SAFE-V8-N1-65$\underline{76}$ 
[22] Jorge-García, D., Estruch-Guitart, V. (2020). Economic valuation of ecosystem services by using the analytic hierarchy process and the analytic network process. comparative analysis between both methods in the Albufera Natural Park of València (Spain). International Journal of Design \& Nature and Ecodynamics, 15(1): 1-4. https://doi.org/10.18280/ijdne. $\underline{150101}$

[23] Nirmala, G., Uthra, G. (2019). AHP based on Triangular Intuitionistic Fuzzy Number and its Application to Supplier Selection Problem. Materials Today: Proceedings, 16: 987-993. https://doi.org/10.1016/j.matpr.2019.05.186

[24] Karimi, H., Sadeghi-Dastaki, M., Javan, M. (2020). A fully fuzzy best-worst multi attribute decision making method with triangular fuzzy number: A case study of maintenance assessment in the hospitals. Applied Soft Computing, 86: 105882. https://doi. org/10.1016/j.asoc.2019.105882

[25] Tseng, M.L., Lim, M., Wu, K.J., Zhou, L., Bui, D.T.D. (2018). A novel approach for enhancing green supply chain management using converged interval-valued triangular fuzzy numbers-grey relation analysis. Resources, Conservation and Recycling, 128: 122133. http://doi.org/10.1016/j.resconrec.2017.01.007

[26] Borovička, A. (2019). New approach for estimation of criteria weights based on a linguistic evaluation. Expert Systems with Applications, 125: 100-111. https://doi.org/10. $\underline{1016 / j . e s w a .2019 .01 .069}$

\section{Authors}

Lin Wang Ph.D., associate professor, high-level talent of Hainan Province, creator of Neutralization System, Tai Chi Yoga, First-grade instructor of National Health Qigong, psychological counselor, and senior Yoga Instructor. With more than ten years of experience in teaching Tai Chi abroad, he is now engaged in theoretical and practical research of Tai Chi yoga, meditation and decompression, Health Qigong, and physical and mental growth. He had given over a hundred lectures at home and abroad, published many papers, including 7 monographs, 2 papers included in international conferences, led in 1 provincial-level project, and won 2 national second prizes and 1 third prize for his papers. He received his bachelor degree of Physical Education and Training from Hebei Sport University, master degree of Physical Education and Training from Hebei Normal University, and $\mathrm{PhD}$ of theories and methods of physical education, sports training, health care and adaptive sports from Russian National University of Physical Education, Sports and Tourism. His working experience includes: 1998-1999, Hebei Institute of Physical Education; 2001-2002, Hebei Normal University; 2003-2016, General Manager and Head Coach of Russian Tai Chi Center "Тайцзи Центр"; Since 2017, Hainan College of Vocation and Technique (email: wanglintaichi@163.com).

Weifeng Deng female, Han nationality, was born in December 1976. She graduated from English Department of Hebei Normal University with a bachelor degree in English in July 1999. In the same year, she was admitted to Hebei Normal University for a master degree in English Language and Literature. Since 2000, she was a part-time English teacher of Dingzhou Normal School for two consecutive years. In 2002, She studied in Russia for a doctoral degree. From April 2003 to November 2007, she also worked as a part-time Chinese teacher in various schools and training courses in Moscow. After returning to China in 2007, She worked as a 
translator for English and Russian. From September 2014 to July 2015, she was an English teacher and counselor in Classes 1, 2 and 3 for the 2014 Simultaneous Interpretation majors in Hebei Foreign Studies University. Since July 2015, she has been a full-time English teacher in the Public Department of Hainan College of Vocation and Technique (email: 18976257477@163.com).

Haijin Pan male, lecturer in Hainan Vocational University of Science and Technology. He received his bachelor's degree of physical education from Hainan Normal University. He is now a special Olympic swimming coach of the Hainan Disabled Persons' Federation, an intermediate national swimming coach, a grade-5 lifeguard, and a full-time teacher in Hainan Vocational University of Science and Technology. Awards: won the eighth place in the "An Tuo Kuai" Marathon in Hainan Province in 2008; selected as the Excellent Teacher of 2012; won the fifth place in the 2018 National Disabled Swimming Championships (as the coach); won 1 gold medal, 2 silver medals, and 7 bronze medals in the 10th Paralympic Games of the People's Republic of China and the 7th Special Olympics Games in 2019 (as the coach); selected as the Excellent CPC Member of 2019 (email: 938770234@qq.com).

Xue Deng female, associate Professor in Xingtai Polytechnic College, engaged in college Physical Education and Sports Economy research for more than 10 years. She had published dozens of papers, presided over and participated in 4 provincial-level programs, and 2 municipal-level programs, won first prize in the 18th competition of Hebei Province School Sports and Health Research Papers. Learning experience: 2000-2004, undergraduate of Physical Education major in Hebei Normal University; 2004-2007 postgraduate of Physical Education and Training major in Hebei Normal University. Working experience: 2007-present, teaching at Xingtai Polytechnic College (email: $315038548 @$ qq.com).

Article submitted 2020-12-10. Resubmitted 2021-02-01. Final acceptance 2021-02-03. Final version published as submitted by the authors. 